\title{
Ionic Conductivity of PVC Based Microporous Polymer Membrane Electrolyte
}

\author{
ASHWINI S. MAHALLE* ${ }^{*}$ and VIJAYA S. SANGAWAR \\ Department of Physics, Polymers and Nanomaterials Research Lab, \\ Govt. Institute of Science \& Humanities, Amravati-444604 (M.S.), India \\ ashwini_mahalle@rediffmail.com
}

Received 14 June 2012 / Accepted 8 July 2012

\begin{abstract}
A microporous polymer membrane based on polyvinyl chloride (PVC) was obtained by a novel polymer dissolution technique in different compositions of (PVC-PVA). The structural study of the prepared PVC microporous membrane was carried out by x-ray diffraction. TGA/DTA analysis reveals that the microporous polymer membrane is thermally stable up to $600{ }^{\circ} \mathrm{C}$. Ionic conductivity of polymer membrane electrolytes have been determined by impedance studies in the temperature of 303$343 \mathrm{~K}$ by varying the PVA content in PVC matrix. The ionic conductivity at room temperature was significantly enhanced about $5.431 \times 10^{-4} \mathrm{~S} / \mathrm{cm}$ when the weight ratio of PVA was $40 \mathrm{wt} \%$. Finally the effect of different lithium salt concentration was also studied for the microporous polymer electrolyte of high ionic conductivity system. A maximum ionic conductivity of $1.29 \times 10^{-3} \mathrm{~S} / \mathrm{cm}$ was obtained for $3 \mathrm{M} \mathrm{LiClO}_{4}$ electrolyte solution at ambient temperature.
\end{abstract}

Keywords: Microporous polymer membrane, XRD, TGA/DTA, Ionic conductivity

\section{Introduction}

In the recent years, there has been a tremendous interest in the preparation of polymer electrolytes with high ionic conductivity, good mechanical strength and thermal stabilities because these polymer electrolytes play a major role in solid-state batteries, electrochromic windows, sensors, fuel cells etc. ${ }^{1}$. Poly (vinyl chloride) (PVC) can act as a mechanical stiffener in the electrolyte due to its immiscibility with the plasticizer. A PVC-based polymer electrolyte system plasticized with ethylene carbonate and propylene carbonate has been reported ${ }^{2}$ to be applicable to lithium metal and lithium ion secondary batteries.

These plasticized polymer electrolytes could show a room temperature ionic conductivity of the order of $10^{-3} \mathrm{~S} / \mathrm{cm}$.However these polymer electrolytes could not completely satisfy the requirements on properties such as good mechanical strength, high ionic conductivity, tensile strength and good abrasion resistance ${ }^{3}$. Microporous polymer membrane electrolytes can be prepared by conventional phase inversion technique ${ }^{4-6}$. However, in this process, due to the use of large amounts of expensive, harmful and flammable solvents, contamination of the porous membrane may take place by the residual solvents. Moreover, preparation of MPEs by conventional phase inversion technology is costly and time consuming. 
Hence in the present investigation we have developed a simple, reliable, time saving and industrially feasible process for the fabrication of microporous polymer membrane, PVC based microporous membrane was prepared by extracting PVA from PVC-PVA blend film by using simple dissolution of PVA in DMSO. Moreover these membranes can be easily detached from the substrate and could be used for Li battery applications or many other applications depending upon the type of dopant to be used. The membrane morphology was investigated by XRD analysis. The polymer PVA is a quick dissolver and it can be easily blended with other polymers, while PVC has been chosen because of its high resistance to oxidation, heat released in burning is considerably low hence PVC membranes are suitable for safety reasons in products close to people's daily lives ${ }^{7-9}$.

\section{Experimental}

PVA with an average molecular weight $(1,15,000)$ and PVC with an average molecular wt. (2, 33,000) (Aldrich USA) were used without further purification for the preparation of microporous membranes. The different compositions of PVC based PVC-PVA polymer membrane were prepared by dissolving PVA in required quantity of DMSO and PVC in DMF, these solutions were stirred well for half an hour until the complete dissolution of PVA in DMSO and PVC in DMF have been achieved. Both the solutions were added together and was stirred well and heated continuously at $50{ }^{\circ} \mathrm{C}$ for half an hour until the mixture becomes a homogeneous viscous solution. The viscous solution was poured on a horizontally leveled glass plate to form the films of required thickness. Finally the films were dried at $80{ }^{\circ} \mathrm{C}$ in vacuum oven for 3 hours to remove any further traces of DMSO and DMF. The above prepared cast polymer films were immersed in DMSO for the preferential dissolution of PVA to get uniform microporous membranes of PVC. The thickness of the formed membrane was between the ranges of 195-200 $\mu \mathrm{m}$. Porosity \% and weight uptake of different compositions of PVC based microporous membrane increases with increase in PVA content. The liquid electrolyte used in this study was $1 \mathrm{M}$ $\mathrm{LiClO}_{4}$ in 1:1 (v/v) mixture of propylene carbonate (PC) and diethyl carbonate (DEC). Weight uptake of PVC-PVA blend microporous membranes were measured as a function of soaking time in liquid electrolyte to activate porous polymer membranes for $8 \mathrm{~h}$ and calculated as follows ${ }^{10}$;

$$
\text { Weight uptake }(\%)=\left(\mathrm{W}_{\mathrm{t}}-\mathrm{W}_{0}\right) / \mathrm{W}_{0} \times 100
$$

Where, $\mathrm{W}_{\mathrm{t}}$ and $\mathrm{W}_{0}$ are the weight of the wet and dry polymer membranes, respectively. Porosity of PVC membranes was measured by immersing the membrane into 1-butanol for $2 \mathrm{~h}$ and calculated using the following equation ${ }^{11}$;

$$
\text { Porosity }(\%)=\left(\mathrm{W}_{\mathrm{t}}-\mathrm{W}_{0}\right) / \mathrm{\rho V} \times 100
$$

Where, $\mathrm{W}_{\mathrm{t}}$ and $\mathrm{W}_{0}$ are the weight of the wet and dry polymer membranes, respectively. $\mathrm{V}$ is the apparent volume of the membrane and $\mathrm{P}$ is the density of 1-butanol. X-ray diffraction study has been made to investigate the crystallanity of microporous polymer membrane. TGA/DTA equipment was used at a scanning rate $10{ }^{\circ} \mathrm{C} \mathrm{min}^{-1}$ to find thermal stability of microporous polymer membrane. The ionic conductivity values of PVC based micro-porous polymer electrolyte was evaluated from cole-cole impedance plot using EG \&G electrochemical analyzer in the frequency range of $10 \mathrm{~Hz}$ to $1 \mathrm{Mz}$ with signal amplitude $10 \mathrm{mV}$ by placing the microporous polymer electrolyte in between two stainless steel (SS) disc electrodes in a specially designed cell setup for conductivity studies. 


\section{Results and Discussion}

\section{$X$-ray diffraction analysis}

X-ray diffraction pattern of PVC microporous membrane is presented in Figure 1. X-ray diffraction measurement was carried out using PHILLIPS Holland, XRD system PW 171 diffractometer employed with $\mathrm{Cu}$-anode operated at $30 \mathrm{~K}$.

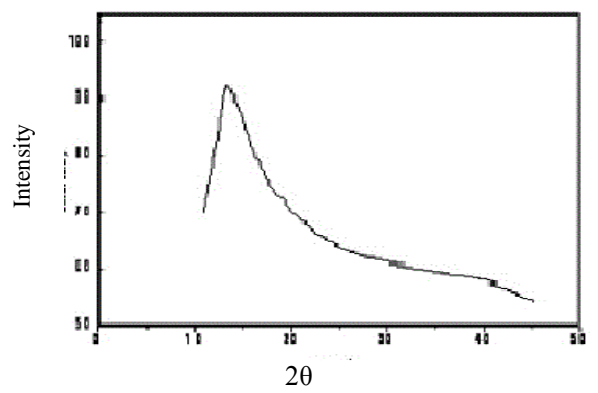

Figure 1. X-ray diffraction pattern of PVC microporous polymer membrane

The diffraction peak was observed at $2 \theta=13.2^{\circ}$ with intensity value which is closely related to the reported value ${ }^{12}$. In polymer complexes, these peaks of PVC appeared as a single broad peak with less intensity indicates that the synthesized microporous PVC membrane is highly amorphous in nature ${ }^{13}$.

\section{Thermal analysis}

Thermogravimetric analysis (TGA) is one of the powerful tools to determine the stability of polymer and its composites. For lithium battery, thermal stability of the porous polymer membrane is an important parameter to guarantee acceptable performances of the membranes in such applications ${ }^{14}$. TGA/DTA analyses of PVC microporous membrane are shown in Figure 2 and Figure 3. It was observed from Figure 2, a first decomposition was started at the temperature $283{ }^{\circ} \mathrm{C}$ with a weight loss of $45 \%$ was attributed to the presence of moisture at the time of loading the sample and ends at $334{ }^{\circ} \mathrm{C}$. The membrane starts second decomposition at $432{ }^{\circ} \mathrm{C}$, with weight loss of $19 \%$ indicating that the membrane is stable up to $600{ }^{\circ} \mathrm{C}$.

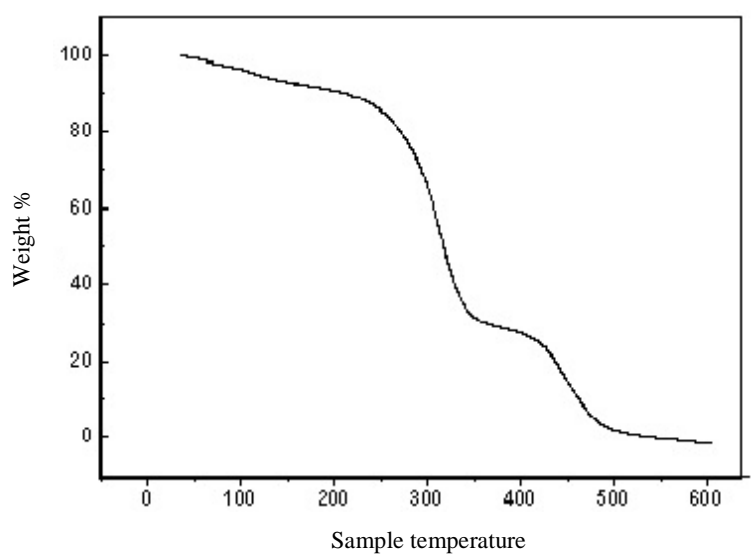

Figure 2. TGA curve for PVC based microporous polymer membrane 
DTA trace shows an exothermic peak around $250{ }^{\circ} \mathrm{C}$ indicative of the maximum weight loss rate of the decomposition of PVC corresponds to the rapidest degradation temperature of the stage. Pure PVC decomposes completely at $500 \pm 2{ }^{\circ} \mathrm{C}$ and residue remains as carbon ${ }^{15}$. The surface morphology PVC based microporous membranes were studied by scanning electron microscopy (SEM) using Jeol model JSM 6390 LV.

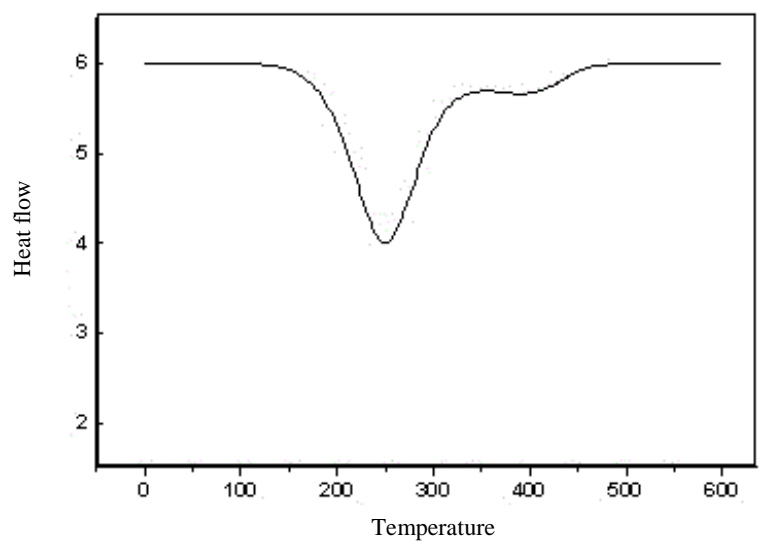

Figure 3. DTA curve for PVC based microporous polymer membrane

\section{SEM analysis}

SEM photograph of the microporous polymer membrane of high conductivity system PVCPVA (60-40) \% and PVC-PVA (50-50) \% of PVA are shown by Figure 4 (a) and Figure 4 (b). It can be seen from figures that pores in (60-40) \% and (50-50) wt.\% of (PVC-PVA) are largely cylindrical shaped and interconnected. The pore size of microporous polymer membrane increases with increase in removal of PVA content. Hence the uptake of electrolyte solution by microporous polymer membrane is higher than that of conventional polymer film.
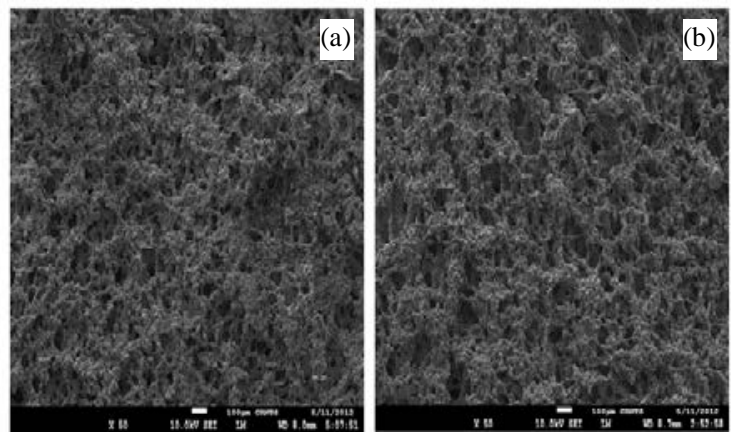

Figure 4. SEM photograph for microporous polymer electrolyte (a) (60-40) wt.\% \& (b) for (50-50)wt.\% of (PVC-PVA) blend ratio

\section{Porosity and electrolyte uptake of microporous polymer membrane}

Figure 5(a) displays the variation of porosity of PVCs microporous membranes. It can be observed from figure that with gradual increase in PVA weight ratio, porosity first increases as a function of PVA concentration and reaches maximum (53-2\%) when the weight ratio of PVA is $50 \%$ and subsequently decreases at higher weight ratio of PVA. 

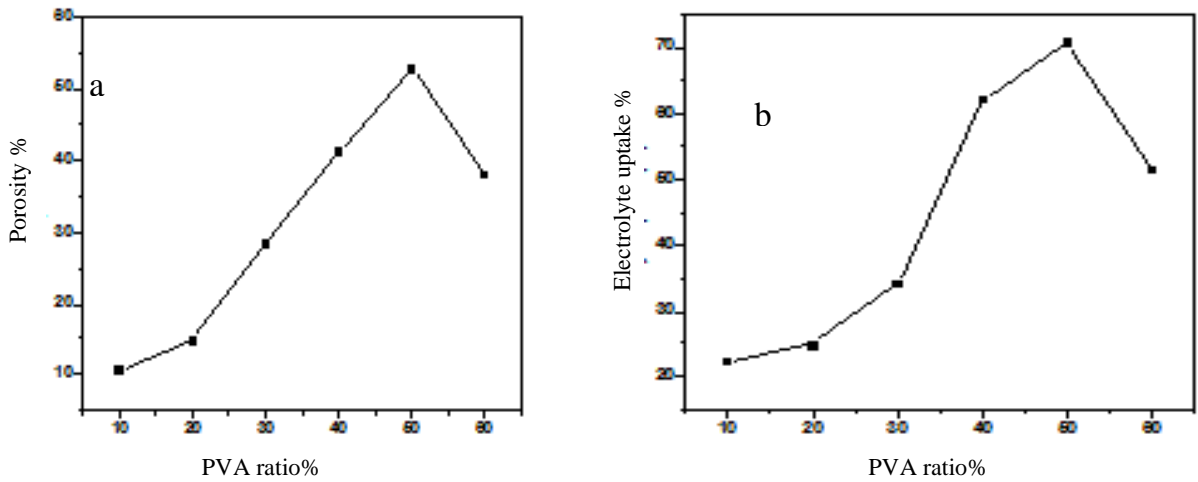

Figure 5. Porosity and liquid electrolyte uptake of PVC microporous membrane as a function of PVA wt. ratio

The liquid electrolyte uptake plot of PVC based microporous membranes is shown in Figure 5(b). The figure shows that the liquid electrolyte uptake of PVC microporous membranes is greatly influenced by PVA concentration and is consistent with the variation of porosity of the membranes. As \% of PVA content increases resulting in greater porosity, the liquid electrolyte uptake also increases, suggesting that PVC microporous membranes can store more liquid electrolytes when its porosity increases ${ }^{16}$. Beyond $50 \mathrm{wt}$. \% of PVA content both porosity and liquid electrolyte uptake decreases which was attributed to decrease in mechanical strength of the membrane and irregularity in pore size.

\section{Conductivity studies}

Ionic conductivity values of PVC based micro-porous polymer electrolyte was evaluated from cole-cole impedence. The ionic conductivity of PVC based polymer electrolytes is calculated from $\sigma=1 / \mathrm{RbA}$, where $\mathrm{Rb}$ is the bulk resistance of the polymer electrolyte and ' $\mathrm{l}$ ' and ' $\mathrm{A}$ ' are the thickness and known area of the polymer electrolyte film respectively. The conductivity data of microporous polymer membrane electrolyte are given in Table 1 . It can be seen from the Table 1, that the increase of PVA content in PVC matrix, increases the conductivity due to the higher uptake of electrolyte by PVC in $1 \mathrm{M} \mathrm{LiClO}_{4}$ but decreases the mechanical strength. However the blend ratio of $60 \mathrm{wt}$. \% of PVC and $40 \mathrm{wt} \%$ of PVA has exhibited high ionic conductivity of $5.431 \times 10^{-4}(\mathrm{~S} / \mathrm{cm})$ and sufficient mechanical strength at room temperature than all other micro-porous membrane electrolytes. Hence above blend ratio is chosen for optimized system.

Table 1. Ionic conductivity values of PVC microporous polymer membrane soaked in $1 \mathrm{M}$ concentration of $\mathrm{LiClO}_{4}$ electrolyte Solution at room temperature

\begin{tabular}{ccccc}
\hline S. No & PVC & PVA & Conductivity, $\mathrm{S} \mathrm{cm}^{-1}$ & Film strength \\
\hline 1 & 100 & 0 & $0.129 \times 10^{-4}$ & excellent \\
2 & 90 & 10 & $0.334 \times 10^{-4}$ & Excellent \\
3 & 80 & 20 & $0.876 \times 10^{-4}$ & Good \\
4 & 70 & 30 & $2.638 \times 10^{-4}$ & Good \\
5 & 60 & 40 & $5.431 \times 10^{-4}$ & Good \\
6 & 50 & 50 & $5.412 \times 10^{-4}$ & Poor \\
\hline
\end{tabular}


The effect of different lithium salt concentrations in the optimized system of PVC-PVA microporous polymer electrolyte was studied similar to the above conducted experiment, the ionic conductivity of polymer membrane soaked in $1 \mathrm{M}, 1.5 \mathrm{M}, 3 \mathrm{M}, 3.5 \mathrm{M}$ of $\mathrm{LiClO}_{4}$ electrolyte solution at various temperatures ranging from 303 to $343 \mathrm{~K}$ is given in Table 2 . It can be seen from the table, the conductivity increases with increase in temperature for the all concentration ${ }^{17}$. Hence the polymer electrolyte obeys the Arrhenius relation. It is due to the amorphous nature of the present polymer electrolyte which facilitates the fast $\mathrm{Li}$ ion motion in the polymer network and also it provides a higher free volume on increasing the temperature $^{18}$.

Table 2. Ionic conductivity values of PVC microporous membrane soaked in different concentration of $\mathrm{LiClO}_{4}$ electrolyte solution at various temperatures

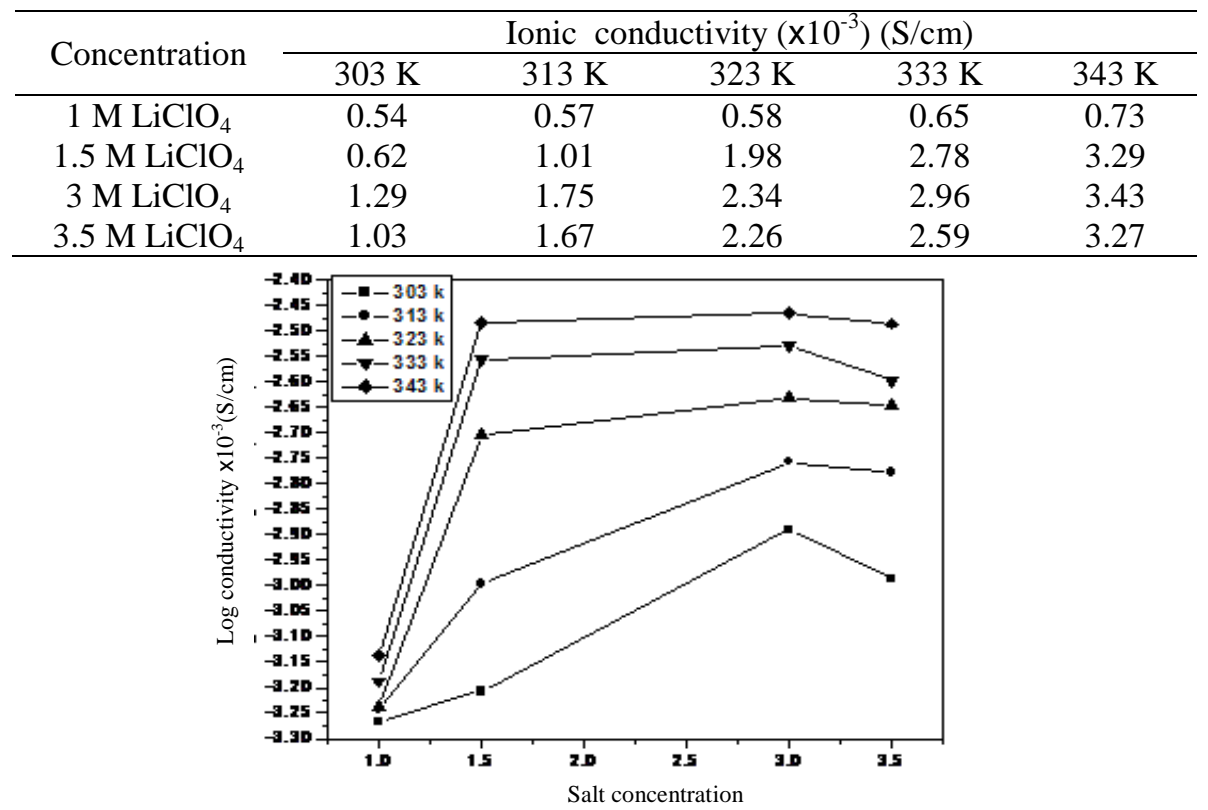

Figure 6. Dependence of ionic conductivity on salt concentration for PVC microporous polymer electrolyte at various temperatures

The ionic conductivity vs. salt concentration (mole fraction) for (60-40) wt. \% system of (PVC-PVA) at various temperatures of $303 \mathrm{~K}-343 \mathrm{~K}$ is shown in Figure 6. The ionic conductivity for the PVC microporous polymer electrolyte increases with the increase in $\mathrm{Li}$ salt concentration up to $3 \mathrm{M} \mathrm{LiClO}_{4}$. The microporous polymer electrolyte consists of $3 \mathrm{M}$ $\mathrm{LiClO}_{4}$ electrolyte solution has high ionic conductivity of $1.29 \times 10^{-3} \mathrm{~S} / \mathrm{cm}$ at room temperature. Beyond this concentration $\left(3 \mathrm{M} \mathrm{LiClO}_{4}\right)$ ionic conductivity decreases .This is due the formation of ion pairs and the ion triplets, which causes constraints in the polymer segmental motion and also retards the ionic mobility due to the increase in crystalline nature of microporous polymer electrolyte ${ }^{19}$.

\section{Conclusion}

1. It is possible to prepare PVC based microporous polymer membrane electrolyte by novel polymer dissolution technique. 
2. The x-ray diffraction peak was observed at $2 \theta=13.2{ }^{0}$ with less intensity indicates that the synthesized microporous PVC membrane is highly amorphous in nature.

3. The microporous polymer membrane has thermal stability up to $600{ }^{\circ} \mathrm{C}$.

4. SEM micrographs clearly show the increase in pore size with increase in removal of PVA content. The increased pore size results in an increase in ionic conductivity as confirmed by a.c. impedance analysis.

5. The maximum ionic conductivity of $5.431 \times 10^{-4} \mathrm{~S} / \mathrm{cm}$ is observed for (60-40) wt $\%$ blend ratio of PVC- PVA at room temperature for $1 \mathrm{M} \mathrm{LiClO}_{4}$ concentration and has sufficient mechanical strength.

6. The effect of Li salt concentration in the polymer matrix on ionic conductivity reveals that the ionic conductivity increases with the increase in Li salt concentration up to $3 \mathrm{M}$ $\mathrm{LiClO}_{4}$. The microporous polymer electrolyte consists of $3 \mathrm{M} \mathrm{LiClO}_{4}$ electrolyte solution has high ionic conductivity of $1.29 \times 10^{-3} \mathrm{~S} / \mathrm{cm}$ at room temperature.

\section{References}

1. Vincent C and Scrosati B, Modern Batteries, An introduction to electrochemical power sources, John Wiley and sons: New York, 1997, 181.

2. Stephan A.M, Prem Kumar, Renganathan N G, Pitchumani S, Thirunakaran R and Muniyandi N, J Power Sources, 2000, 89, 80-87.

3. $\quad$ Min H S, Kim D W and Ko J M, J Power Sources, 2003, 469, 119-121.

4. Wienk I M, Boom R M, Beerlage M A M, Bulte A M W, Smolders C A and Strathmann H, J Membrane Science, 1996, 113, 361-371.

5. Pasquier A D, Warren P C, Culver D, Gozdz A S, Amatucci G G and Tarascon J M, Solid State Ionics, 2000, 135, 249-257.

6. Zhang S S, Xu K, Foster D L, Ervin M H and Jow T R, J Power Sources, 2004, 125(1), 114-118.

7. Subramanian A, Kalyana Sundram N T and Vijaya Kumar N, Springer-Heidelber., 2006, 12, 175-178.

8. Subramania A, Kalyana Sundram N T and Sukumar N, J Power Sources, 2005(a), 141(1), 188-192.

9. Ding Young and Bikson Benjamin, Elsevier Polymer., 2009, 51(1), 46-52.

10. Vijayakumar G, Karthick S N, Sathiya Priya A R, Ramalingam S and Subramania A, J Solid State Elctrochem., 2008, 12, 11-35.

11. Xi J, Qui X, Li J, Tang X, Zhu W and Chen L J, Power Sources, 2006, 157-501

12. Rajendran S, Ramesh Prabhu and Usha Rani M, Int J Electrochem Sci., 2008, 3, 282- 290.

13. Ramesh S, Geok Bee Teh, Rong-Fuh Louh, Yong Kong Hou, Pung Yen Sin and Lim Jing Yi, Sadhana - Academy Proceedings in Engineering Science, 2010, 35, 87-95.

14. Paul V McKinney and Carl R Foltz, J Appl Poly Sci., 1967, 11(7), 1189-1197.

15. Thomas R Manley, J Pure App Chem., 1999, 61(8), 1353-1360.

16. Jeon J D, Cho B W and Kwak S Y, J Power Sources, 2005, 143-219.

17. Armand M B, Chabagno J M and Duclot M J, Fast-ion transport in solid; Mundy J N and Shenoy G, North-Holland, Amsterdam, 1979, 131.

18. Ratner M A and Shriver D F, Chem Rev., 1988, 88, 109.

19. Subramania A, Kalyana Sundram N T and Sukumar N, J Power Sources, 2005(b), 141(1), 188-192. 